\title{
VARIETY OF DISPLACEMENT DEPENDENT DEVICES USED FOR BRIDGES AND VIADUCTS CERTIFIED BY ICECON CERT SRL
}

\author{
ALEXANDRU Carmen \\ Ph.D, Dynamic behavior of structural systems, ICECON SA, Bucharest, Romania, \\ carmen.alexandru@icecon.ro
}

\begin{abstract}
The paper is specially addressed to the seismic device manufacturer, designers and end users of these products, to explicitness the provisions of EN 15129:2009 regarding the tests shall be performed for the displacement depended devices used for bridges and viaducts. Are presented some of examples of dynamic tests carried out under the supervision of the certification body ICECON CERT SRL for the assessment and verification of constancy of performance, based on the evaluation of conformity procedures indicated in the reference document and the regulation EU no (305)/2011.
\end{abstract}

Key words: dynamic, displacement, bridge, viaduct

\section{Introduction}

The displacement dependent devices can be linear and non linear anti-seismic devices and are not carry vertical loads, whose behavior is mainly dependent on displacement rather than on velocity, for use in structures erected in seismic areas in accordance with EN 1998.

Linear devices (LD) are characterized by a linear or quasi-linear behavior and are used to change in a favorable way the dynamic characteristics of a structural system. Non-linearity and/or energy dissipation are compatible with the linear modeling for design analyses of the structural systems including these devices. The behavior of these devices is characterized by a force/displacement law as in figure 1:

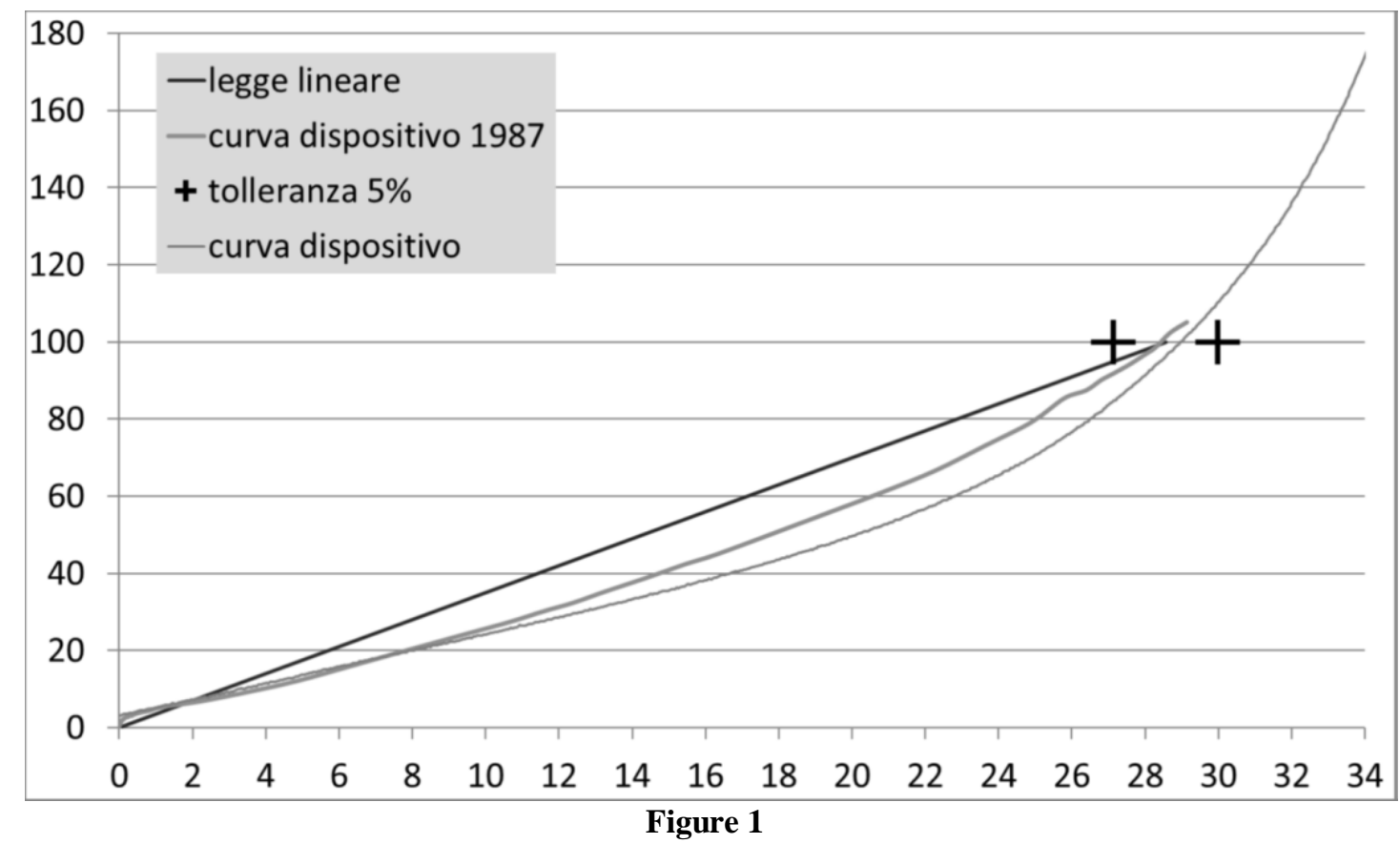

Non Linear Devices (NLD) are characterized by a strongly non linear behavior and are used to change the dynamic characteristics of a structural system, by introducing significant non-linearity and/or 
energy dissipation, which should be appropriately taken into account in the non linear modeling for design analyses of the structural systems including these devices.

figure 2.

The hysteretic behavior of these devices is characterized by a force/displacement behavior as in

The behavior of a DDD is identified by the effective stiffness $K_{\text {eft }}$ and the effective damping $\xi_{\text {eftb }}$, as well as by the first branch stiffness $K_{1}$ and the second branch stiffness $K_{2}$ in the case of a NLD.

A linear device has both the equivalent damping of the hysteretic energy dissipation $\xi_{\text {effb, }}$ less than $15 \%$ and the ratio $\left|K_{\text {effb,h- }} K_{1, \mathrm{~h}}\right| / K_{1, \mathrm{~h}}$ less than 0,2 .

In order to assure a stable behavior under cyclic loading, variations in a series of load cycles relevant to the same displacement shall be limited as follows:

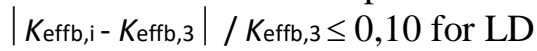

(1)

$\left|K_{2, i}-K_{2,3}\right| / K_{2,3} \leq 0,10$ for NLD

$\left|\xi_{\text {effb,i }}-\xi_{\text {effb, } 3}\right| / \xi_{\text {effb, } 3} \leq 0,10$ for LD and NLD

(3)

where subscript 3 is relevant to quantities at the 3 rd load cycle and subscript $i$ is relevant to quantities at the $\mathrm{i}$-th load cycle of an experimental test, excluding the 1 st cycle $(i \geq 2)$.

The materials used for displacement dependent devices in parts playing different functions. Two main functions can be distinguished: "core" function, characterizing the cyclic seismic behavior of the device, and structural function. Can be used elastomer, steel and other materials (special steel, stainless steel, SMA, visco-elastic polymeric materials).

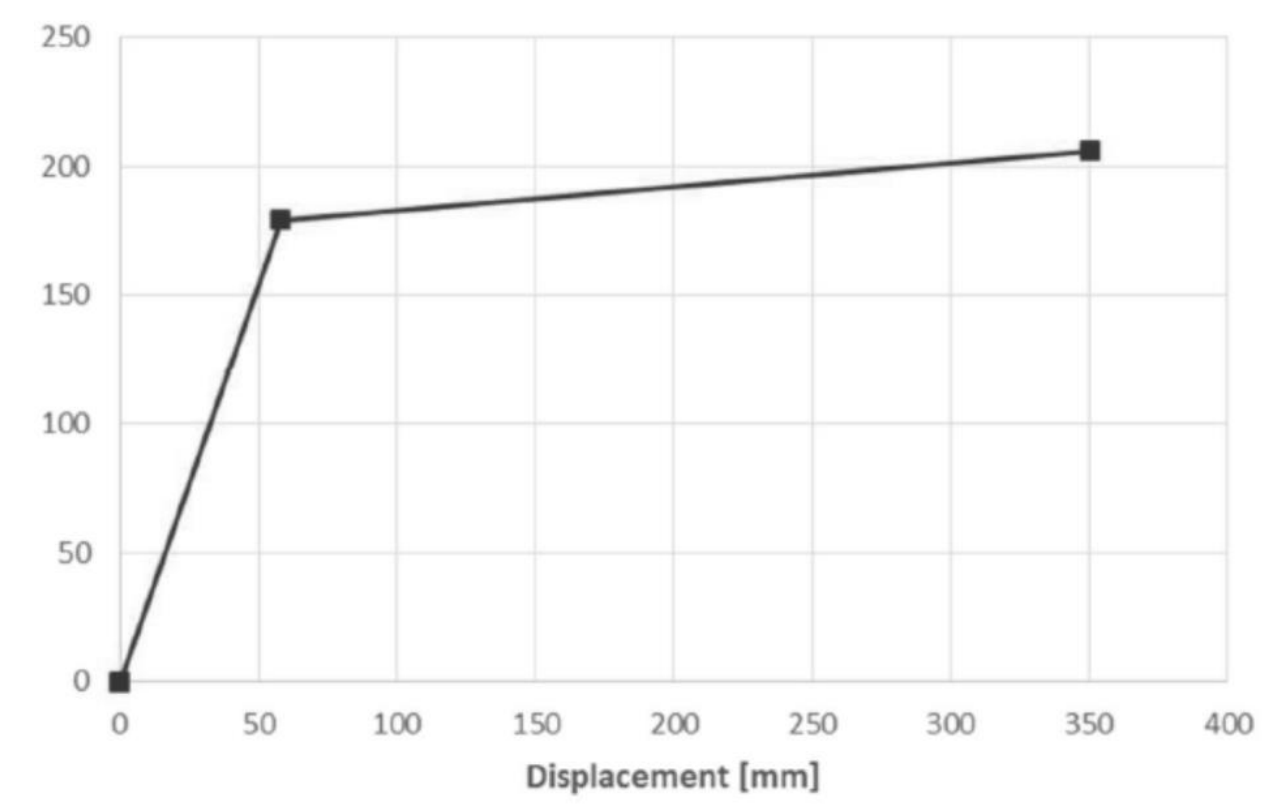

Figure 2

\section{Testing}

The experimental tests are be carried out by imposing cyclic deformations according to EN 15129:2009. During the tests, the values of forces and displacements are be continuously recorded, thus characterizing the entire course of the successive cycles. Tests are performed on complete devices.

Mechanical tests include:

- Type tests of materials;

- Factory production control tests of materials;

- Type tests of devices;

- Factory production control tests of devices. 
The type tests of materials are performed to demonstrate conformity with requirements established as specified in EN 15129:2009.

Type tests of devices are performed whenever new devices with an internal or external geometry, materials or kind of constraints different from those already qualified are designed.

At least one prototype device it is tested. Devices used for prototype tests are not installed in the structure, unless the mechanical characteristics of the device are not affected by the test or are fully recovered, e.g. by substitution of the core elements. Devices are qualified together with their connection system.

Testing procedures are such that the working conditions and fixings of the device are reproduced. In general, type tests are carried out on full-scale specimens. In general, dynamic tests are carried out to reproduce the actual working conditions of the devices.

\section{Linear devices testing}

The tests have been carried out on the device type Linear Dependent Device $\phi 340 x 70$, in ISOLAB laboratory under the supervision of ICECON CERT SRL. The tests have been carried out using the contrast structures of $1000 \mathrm{kN}$ vertical load capacity, along with the static jacks and dynamic actuators.

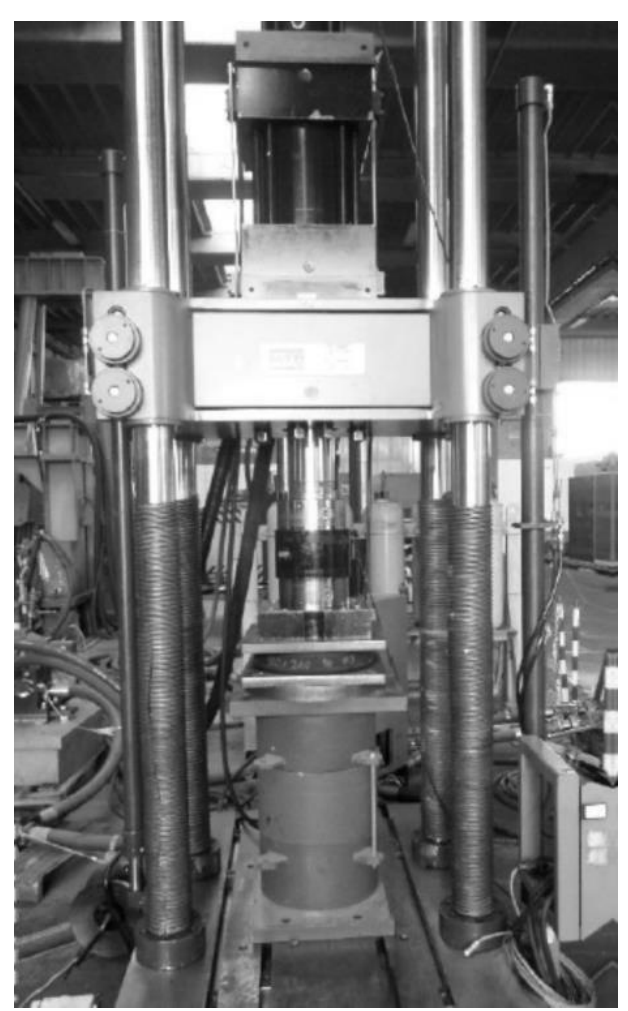

Figure 3

The device consists of two square-shaped external plates on which three longitudinal guides are welded. On these elements are stacked the elastic rubber rings alternating with round steel plates. Laterally four turnbuckles are positioned to be used to adjust the length of the device, as a function of the thermal expansion of the viaduct at the time of placing. The connection to the structure is made by bolts, as in the figure 4 . 


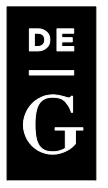

ACTA UIVERSITATIS CIBINIENSIS - TECHNICAL SERIES

Vol. LXIX 2017

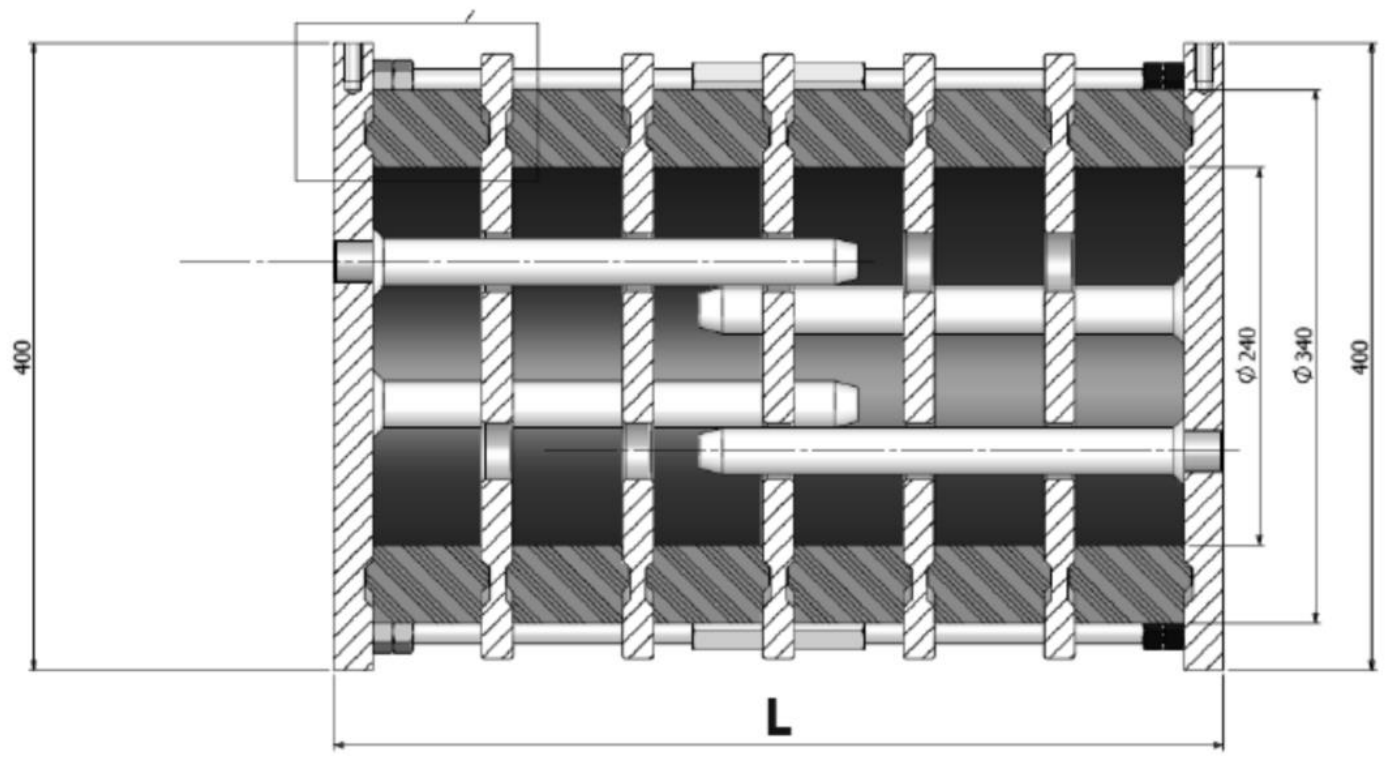

Figure 4

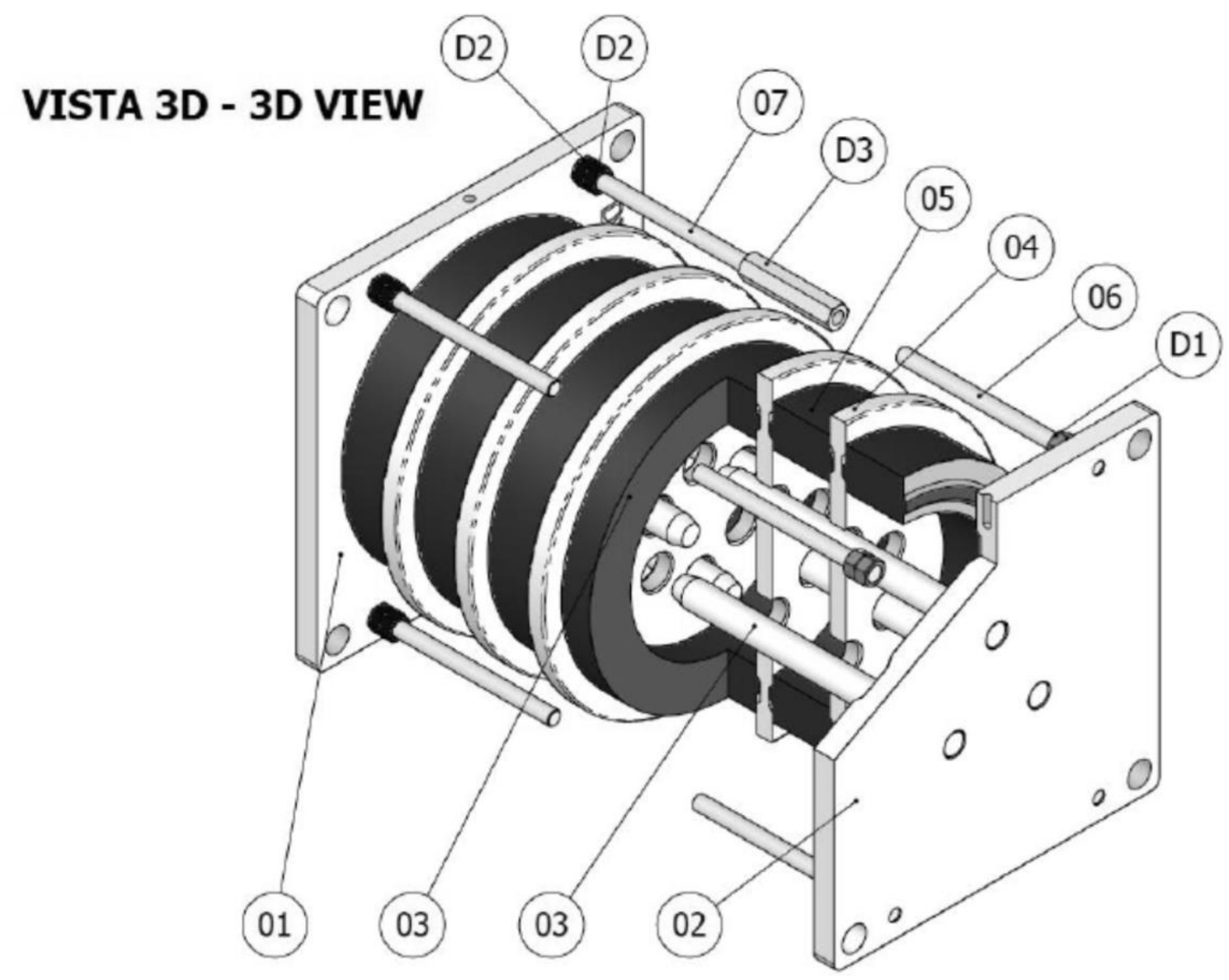

Figure 5

The test procedure included the steps listed below: 


\section{ACTA UIVERSITATIS CIBINIENSIS - TECHNICAL SERIES}

Vol. LXIX 2017

a) Evaluation of the force-displacement cycle

The test specimen was subjected to the application of sinusoidal cycles of increasing amplitude at $25 \%, 50 \%$, and $100 \%$ of the maximum displacement, which was equal to $\mathrm{d}_{\mathrm{bd}}$. Five cycles for minimum and intermediate amplitude, and ten cycles for the maximum amplitude were applied.

RESULT: The device did not break during consecutive cycles. The device kept the characteristics

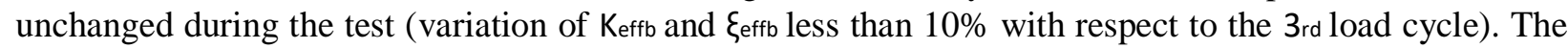
Keffb of 3 rd cycle at dbd displacement was inside the tolerance limits of $\pm 15 \%$ of theoretical values. The $\xi_{\text {effb }}$ of 3 rd cycle at dbd displacement was less of $4 \%$. The evaluation force-displacement T1, T2, T3 hysteretic curve are presented in figure $6,7,8$.

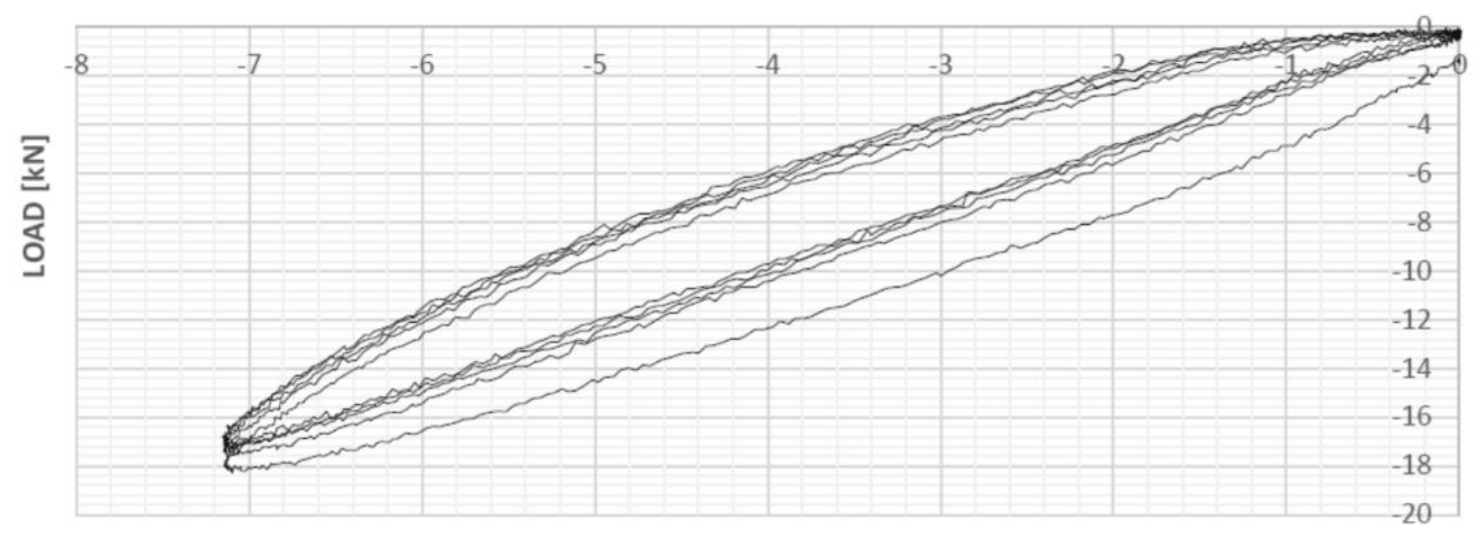

DISPLACEMENT [mm]

Figure 6

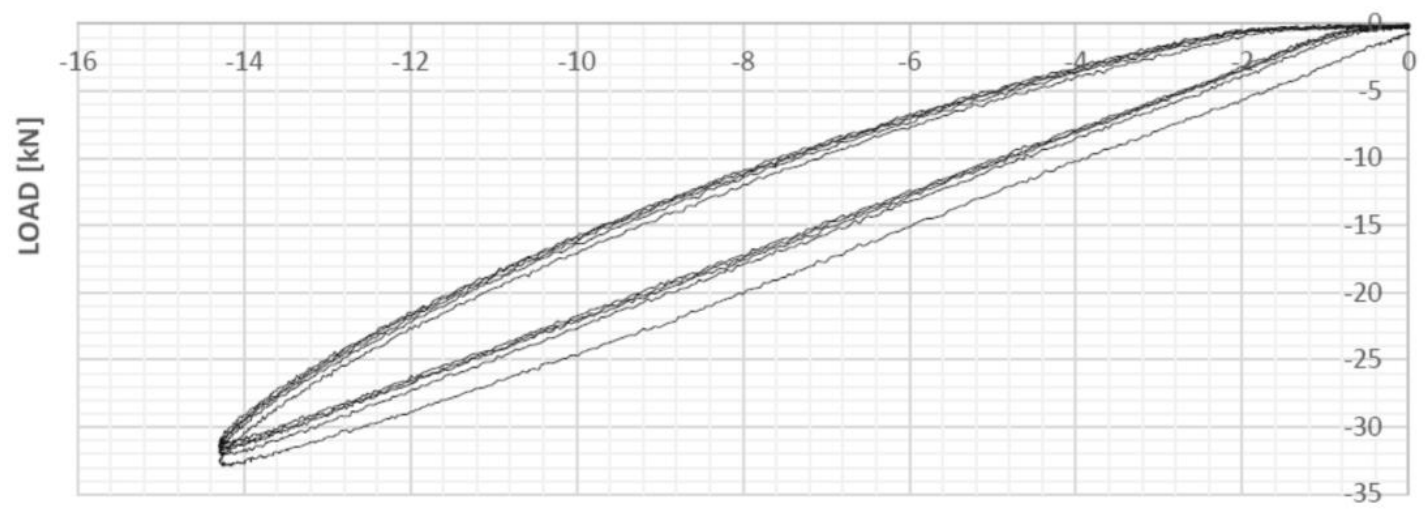

DISPLACEMENT [mm]

Figure 7 
ACTA UIVERSITATIS CIBINIENSIS - TECHNICAL SERIES

Vol. LXIX 2017

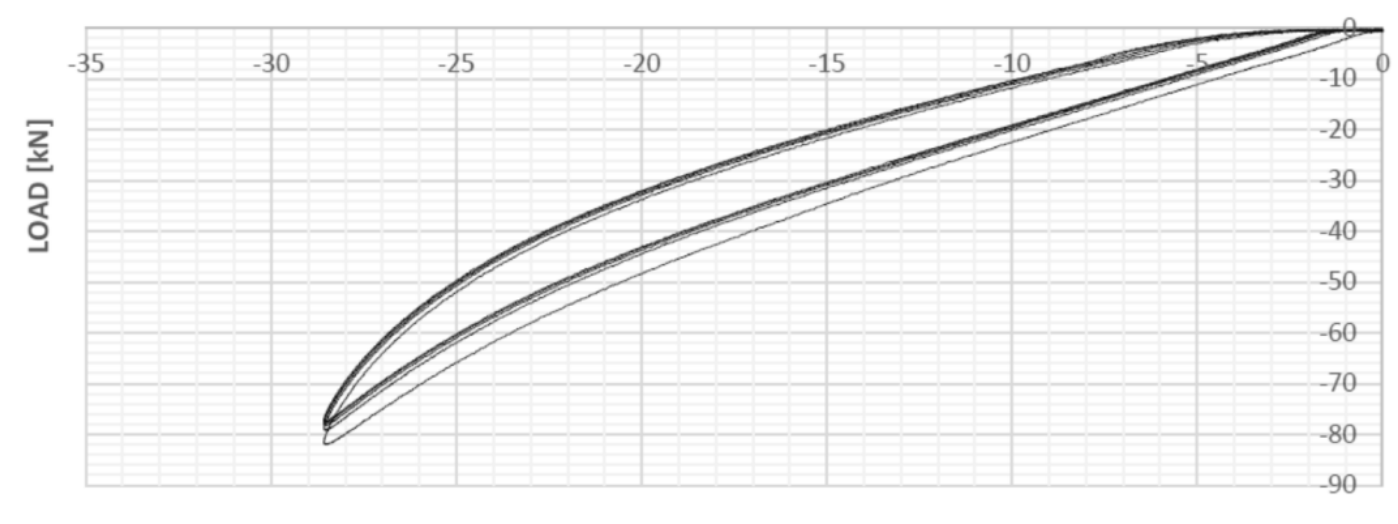

DISPLACEMENT [mm]

Figure 8

b) Ramp test for the static evaluation of the failure displacement

The test specimen was subjected to a monotonic ramp to the maximum displacement $\mathrm{d}_{\mathrm{bd}}$ multiplied $\gamma_{\mathrm{b}}$ and $\gamma_{\mathrm{x}}$ or a force of $\mathrm{V}_{\mathrm{Ed}}$ multiplied $\gamma_{\mathrm{b}}$ and $\gamma_{\mathrm{x}}$ whichever is reached first.

All results have been reported cleared from all machine frictions. All tested devices have been visually inspected before, during and after the tests, to check the presence of possible defects.

RESULT: The force - displacement curve of the device was not show a decreasing trend while increasing the displacement up to the maximum displacement $d_{b d}$ multiplied $\gamma_{b}$ and $\gamma_{x}$ or a force of $V_{E d}$ multiplied $\gamma_{\mathrm{b}}$ and $\gamma_{\mathrm{x}}$ whichever was reached first. The characteristic curve it is presented in figure 9.

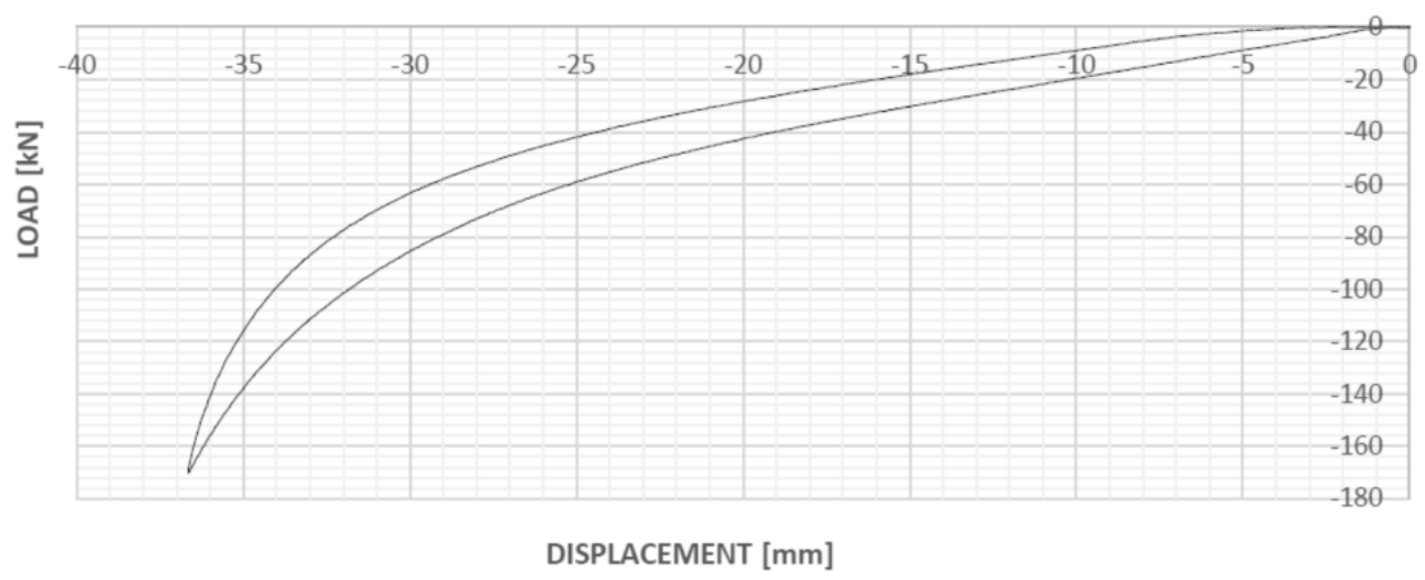

Figure 9

\section{Nonlinear devices testing}

The tests have been carried out on the device type Nonlinear Dependent Device ISOSISM C1, as is presented in figure 10, in ISOLAB laboratory under the supervision of ICECON CERT SRL. The tests have been carried out using the contrast structure of $50000 \mathrm{kN}$ vertical load capacity, along with the static jacks and dynamic actuators, as is presented in figure 9. 
ACTA UIVERSITATIS CIBINIENSIS - TECHNICAL SERIES

Vol. LXIX

2017

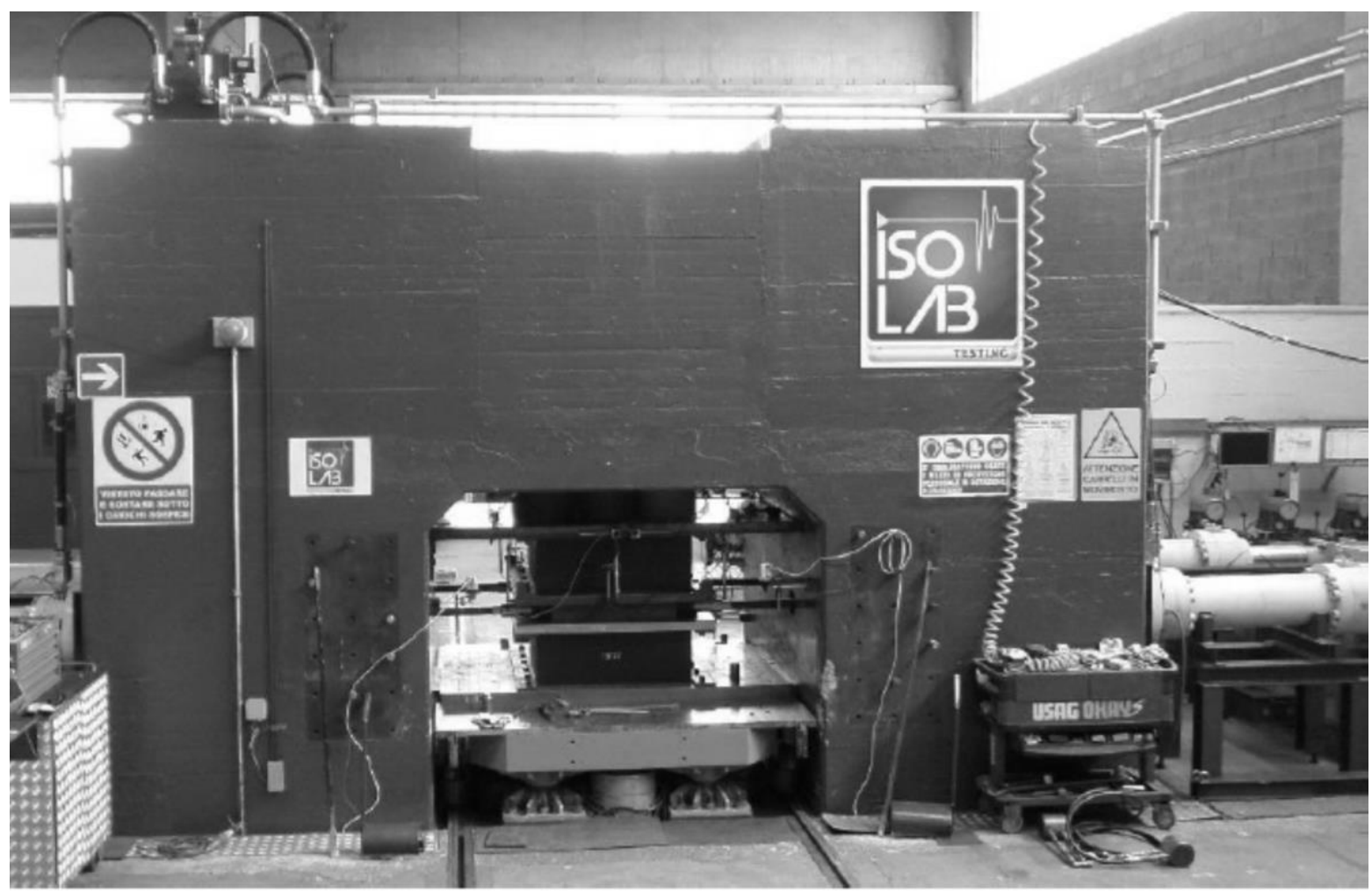

Figure 10

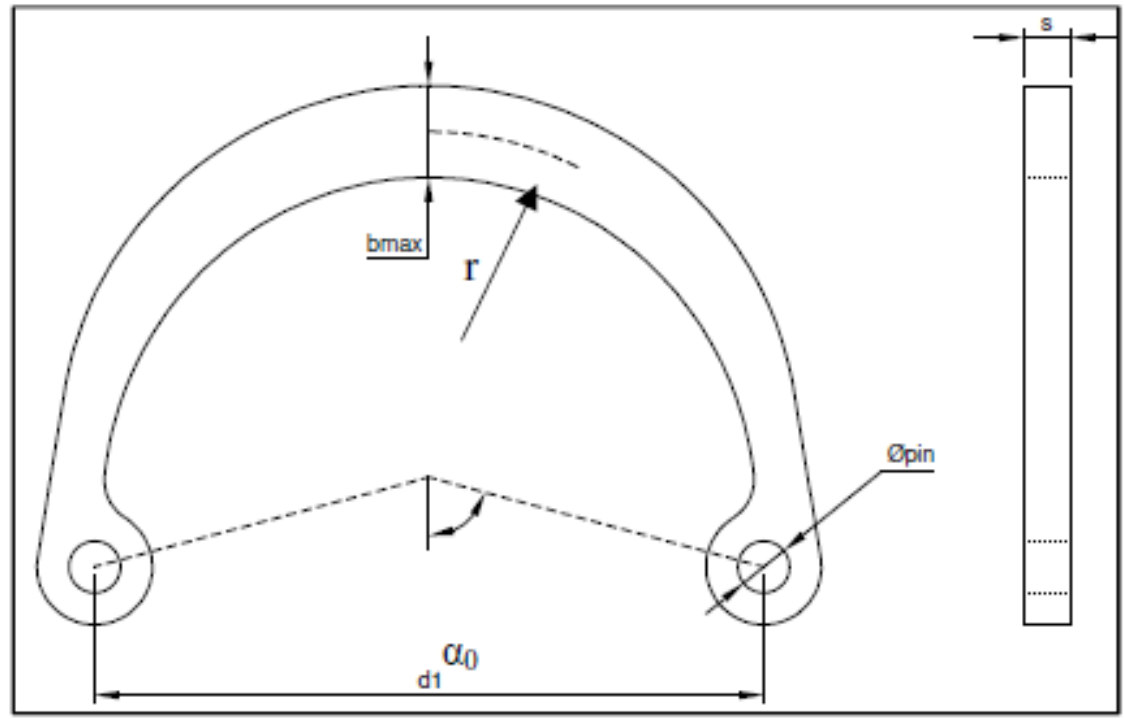

Figure 11

The test procedure included the steps listed below:

a) Evaluation of force-displacement cycle test

The test has been carried out, in accordance with the applicable documents. The test has been performed applying, on a pair of element, five complete reversed cycles, at the following displacements:

- $\pm 0,25 \mathrm{dbd}$

- $\quad \pm 0,50 \mathrm{dbd}$ 


\section{ACTA UIVERSITATIS CIBINIENSIS - TECHNICAL SERIES}

Vol. LXIX 2017

and ten cycles at the design displacement:

- $\quad \pm 1,00 \mathrm{dbd}$

RESULT: All devices are compliant to the requirements of EN 15129. All tested devices have been visually inspected before, during and after the tests. No sign of damage has been detected. The evaluation force-displacement T1, T2 and T3 test curve are presented in the figures 12, 13 and 14.

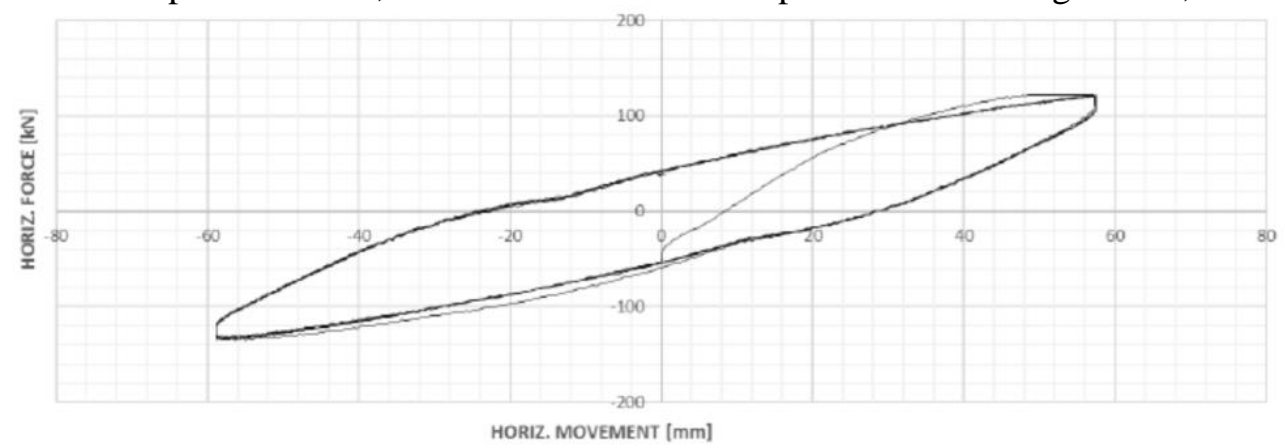

Figure 12

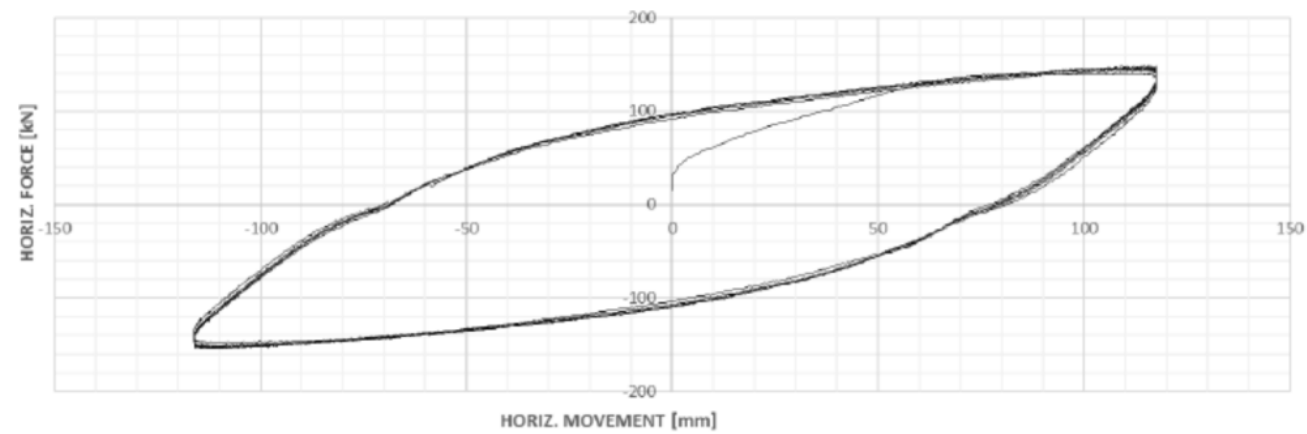

Figure 13

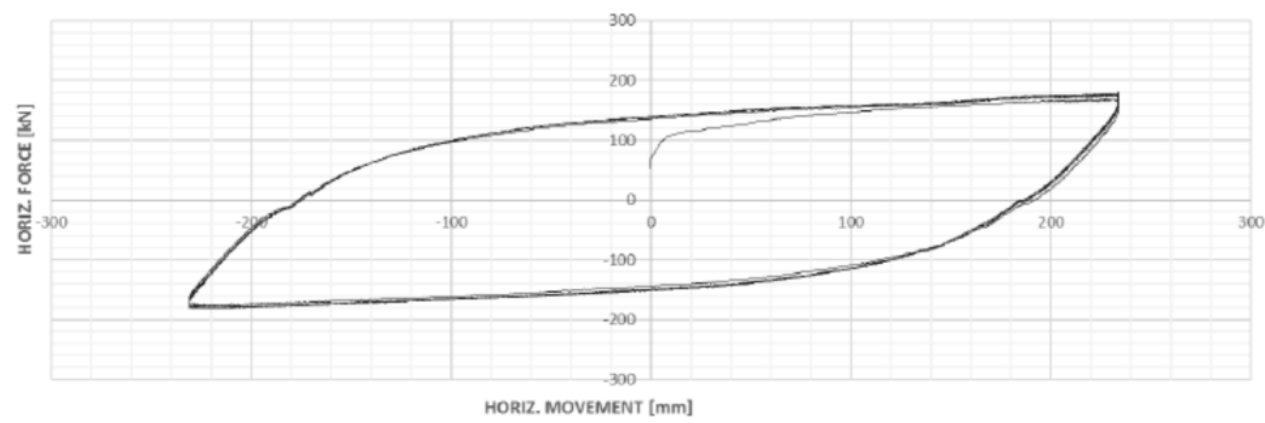

Figure 14

b)Ramp test

This test has been performed applying, on the same pair of element, a monotonic ramp up to reach the expected test displacement $d_{b d} \gamma_{x} \gamma_{b}$ or $V_{E d b} \gamma_{x} \gamma_{b}$.

RESULT: the test results referred at 3 rd cycle of dbd displacement are summarized. In particular, the effective stiffness $K_{\text {eff }}$ at dbd displacement, and effective damping $\beta_{\text {eff }}$ at the same displacement, were listed. The effective stiffness and damping were within the range provided by EN 15129. 


\section{ACTA UIVERSITATIS CIBINIENSIS - TECHNICAL SERIES}

Vol. LXIX 2017

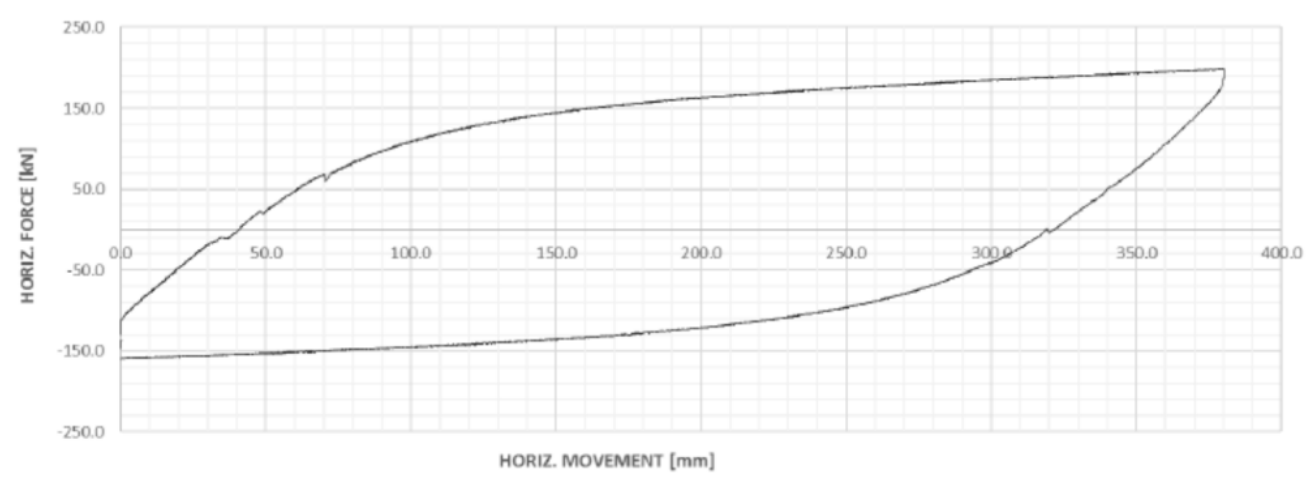

Figure 15

\section{Conclusions}

Displacement dependent devices, both rubber and steel, are characterized by the fact that, at predictable service deformations, they are able they are able to dissipate significant energy to mitigate initial shock in the event of an earthquake. solutions:

In this paper are approached two types of displacement dependent devices, with constructive axial deformation.

a) Linear devices (LD) having as dissipative elements elastomeric disks with symmetrical

b) Non-linear devices (NLD) in the field of plastic, having a bilinear characteristic, with a high energy dissipation capacity at the first seismic shock. the paper highlights:

Based on the experimental results obtained from the tests performed according to EN 15129,

a) hysteretic loops that represent the ability to dissipate for each device separately.

b) maximum deformations of the elements on the stressing direction due to the effect of seismic movement

c) the rigidity characteristics of test cycles, on the basis of which the non-linear character of the devices is established.

\section{References}

1. Polidor, Bratu., Vibrațiile sistemelor elastice, Ed. Tehnică, Bucharest, (2000).

2. Carmen, Alexandru., Analysis of the dynamic behavior of the antiseismic elastomeric isolators based on the evaluation of the internal dissipated energy, Applied Mechanics and Materials, 430, pp. 317-322, DOI: 10.4028/www.scientific.net/AMM.430.317, (2013).

3. Polidor, Bratu., Mecanica sistemelor deformabile. Ed. Impuls, Bucharest, (2006).

4. James, M., Kelly, Dimitrios, A., Konstantinidis, Mechanics of rubber bearings for seismic and vibration isolation, J. Wiley\&Sons Ltd., (2011).

5. Mihai, Ciuncanu., Test performance evaluation for elastomeric anti-seismic devices on specialized stands with controlled generation excitation functions, $22^{\text {th }}$ International Congress on Sound and Vibration, Florance, Italy, (2015)

6. Standard SR EN 15129, Anti-seismic devices, Bucharest, (2010). 